\title{
Characteristic Studies on Novel Biodegradable Polyurethane Thin Films from Soyabean oil
}

\author{
GINJU. M. L' ${ }^{1}$ and S. BEGILA DAVID ${ }^{2}$ \\ ${ }^{1,2}$ Chemistry, Scott Christian College , Nagercoil, Manonmaniam Sundaranar University, \\ Tirunelveli, Abhishekapatti, India. \\ *Corresponding athor E-mail: ginju.ml@gmail.com \\ http://dx.doi.org/10.13005/ojc/350252
}

(Received: January 06, 2019; Accepted: March 07, 2019)

\begin{abstract}
Polyurethane thin film was synthesised from soyabean oil, ethylene glycol, $30 \%$ hydrogen peroxide and isophorone diisocyanate by stepwise polymerisation technique. The biodegradability of the polyurethane film was studied by soil burial test. The chemical resistance of the polyurethane was analysed with different solvents. The polyurethane thin film was characterised with respect to their mechanical properties such as hardness, tensile strength, percentage elongation and young's modulus. These studies revealed that the rigid polyurethane possess good tensile strength and biodegradability. The exothermic and endothermic nature of the polymer showed that the polyurethane was thermally stable. The physical properties such as acid value, saponification value, epoxy value, viscosity and hydroxyl values calculated. The FTIR and NMR spectral studies carried out to identify the nature of the polymer formed. Sem analysis confirmed that the polymer was biodegradable in nature. The shore hardness of the thin film was measured with the help of durometer. The tensile strength increases with increase in concentration. The young's modulus of the thin film was calculated from the tensile strength analysis. The elasticity of the thin film was also measured by using tensile strength measurement. The swelling parameters were studied with polar and organic solvents. The thermal degradation at different time intervals were analysed by TG-DTA analysis.
\end{abstract}

Keywords: Isophorone diisocyanate, Young's modulus, Elasticity, Rigid polyurethane, Soyabean oil, Biodegradability, Thermal degradation, Tensile strength.

\section{INTRODUCTION}

Polyurethanes are synthesised from the reaction between isocyanate and polyol in the presence of a catalyst (or) ultraviolet radiation. Monomeric diisocyanates possess high vapour pressure and act as a strong irritant to skin and eyes. To overcome these problems the isophorone diisocyanates used as industrial coating. ${ }^{1,2,3}$
Soyabean oil is composed of triglycerides of long chain fatty acids. The most common chain lengths in these fatty acids are 18 (or) 20 carbon atoms which can be saturated (or) unsaturated, where unsaturation of the double bonds are located at 9,12 and 15 carbon. Polyurethanes produced from vegetable oils are rigid and used as foams in different fields. .,5, $^{-}$

This is an Open Access article licensed under a Creative Commons license: Attribution 4.0 International (CC- BY). Published by Oriental Scientific Publishing Company @ 2018 
Polyurethanes are first synthesised from a polyol and a diisocyanate by Otto Bayer in the year 1940. Polyurethanes are most versatile polymers due to the flexibility of structure design at the application site. They are mainly used in rigid and flexible foams, coatings, adhesives, sealants, elastomers and binders 7. Some of the researchers have recently started using diethanolamine instead of triethanolamine in the sunflower oil polyol. As a result, diethanolamines of palm oil have been synthesised, on the basis of which polyurethane amides with good characteristics have been obtained ${ }^{8,9,10}$.

The cross linking in Polyurethanes induced with higher $[\mathrm{NCO}] /[\mathrm{OH}]$ ratio. Cross linking at high $\mathrm{R}$ value is reported to proceed through the formation of isocyanate linkage ${ }^{11}$. Brominated castor oil has been investigated as a modificator for preparing flame retardant foam ${ }^{12}$. Drying and semidrying oils such as sesame, sunflower,walnut oil have also been investigated for the preparation of polymer by different methods. Homopolymerisation is not favoured due to steric hindrance of the bulk moieties. Triglyceride oil-based monomers of sunflower oil were prepared ${ }^{13}$.

Among the vegetable oils, castor oil is only one of the oils which contain hydroxyl groups and it can be directly used as a polyol for polyurethane preparation ${ }^{14,15,16}$. The synthesis of -NCO terminated polyurethane and the influence of two different aliphatic diisocyanate viz, hexamethylene diisocyanates and isophorone diisocyanates are reported. Cardanol is made to react with formaldehyde in the mole ratio 1:0.7 in the presence of a dicarboxylic acid catalyst, sebacic acid to form cadanol formaldehyde resin. The resulting methylolated cardanol formaldehyde resin is allowed to condense with hexamethylene diisocyanate (or) isophorone diisocyanate to give the rigid polyurethanes. Commercially available polyol such as polypropylene glycol is also condensed with the same diisocyanates to get tough polyurethanes ${ }^{17}$.

\section{MATERIALS AND METHODS}

The Soyabean oil was purchased from local market, Hydrogen peroxide (30\%) (Rankem), Isophorone diisocyanate (99\%) (Sigma- Aldrich), Ethylene glycol (Rankem), Glacial acetic acid (Rankem).

\section{METHODS}

\section{Synthesis of Epoxidised Soyabean oil}

Soyabean oil was purchased from the local market. $100 \mathrm{~g}$ of soyabean oil was taken in a three necked flask fitted with condenser and thermometer, hydrogen peroxide was added in dropwise for two hours. The setup was kept for ten hours at $60^{\circ} \mathrm{C}$. Finally the epoxidised resin was taken out and washed with warm water and dried at $60^{\circ} \mathrm{C}$ for half an hour in hot air oven.

Step -I - Epoxidation

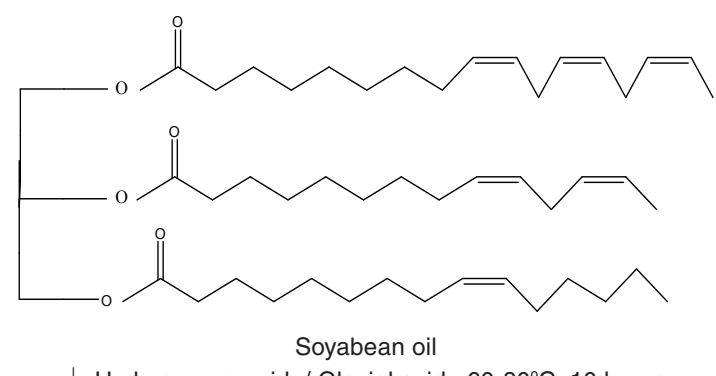

$\downarrow$ Hydrogen peroxide/ Glacial acid , $60-80^{\circ} \mathrm{C}, 10$ hours

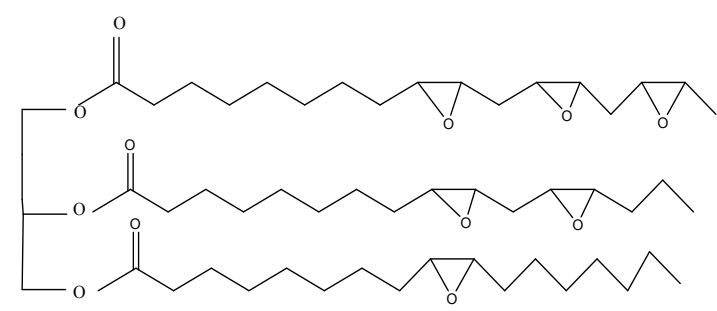

Step: 2 - Polyol Conversion

Epoxidised soyabean oil $\downarrow$ Ethylene glycol, $250^{\circ} \mathrm{C}$

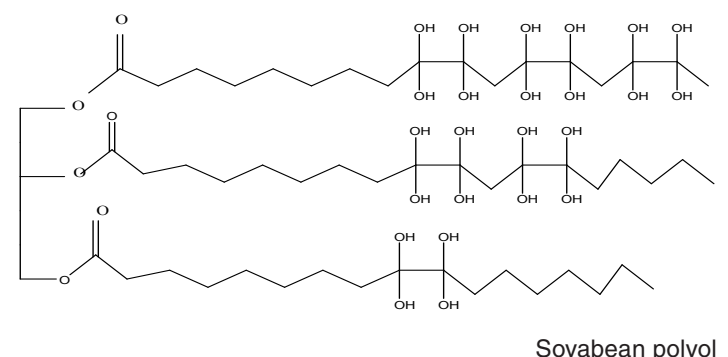

\section{Synthesis of Soyabean polyol}

The epoxidised resin was taken in a three necked flask and ethylene glycol was added in 1:2 ratio. The setup was kept at $250^{\circ} \mathrm{C}$ for five hours. After five $h$ a brown viscous liquid formed and it indicate the formation of polyol.

\section{Manufacture of polyurethane film from soyabean polyol and isophorone diisocyanate}

Polyurethane thin film was manufactured 
by using isophorone diisocyanate and soyabean polyol at different concentration at $60^{\circ} \mathrm{C}$. Then the viscous liquid is transferred into the glass mould. Then the mould is kept at $100^{\circ} \mathrm{C}$ in hot airoven. The polyurethane film was removed from the mould after 48 hours. The Polyurethane thin film of different concentration such as 1:2, 1:3 and 1:4 were synthesised from polyol and monomer Isophorone diisocyanate. Finally the polyurethane sheet was cooled and carefully removed from the mould and labelled as PU1, PU 2 and PU3. Then the synthesised samples were analysed through different analysis.

Table 1: Synthesis of Polyurethane and its composition

\begin{tabular}{ccc}
\hline Sample Code & Composition & NCO/OH Molar ratio \\
\hline PU1 & Polyol + IPDI & 1.2 \\
PU2 & Polyol + IPDI & 1.3 \\
PU3 & Polyol + IPDI & 1.4 \\
\hline
\end{tabular}

\section{RESULT AND DISCUSSION}

\section{FTIR spectral analysis}

The FTIR spectrum of intermediates are obtained by using a Perkin Elmer spectrophotometer. The FTIR spectrum of soyabean oil, resin and polyol are recorded between 500 to $4500 \mathrm{~cm}^{-1}$. The Infrared spectrum of soyabean oil showed a strong absorption band at $3009 \mathrm{~cm}^{-1}$ due to the presence of non conjugated linoleic acid. A pair of peaks observed at $2924 \mathrm{~cm}^{-1}$ and $2852 \mathrm{~cm}^{-1}$ is due to the symmetric stretching- vibration of the aliphatic $-\mathrm{CH}_{2}$ groups. A strong and sharp band at $1743 \mathrm{~cm}^{-1}$ is due to the ester carbonyl group. ${ }^{18,19}$

The absorption band at $1462 \mathrm{~cm}^{-1}$ revealed the presence of $\mathrm{C}-\mathrm{H}$ bending of unsaturated methylene groups. The disappearance of 3009 $\mathrm{cm}^{-1}$ band in epoxidised soyabean oil shows $(-\mathrm{C}=\mathrm{C}-)$ bond. The appearance of band at $922 \mathrm{~cm}^{-1}$ is due to the presence of epoxy group confirmed the epoxidation process. The FTIR spectrum of soyabean polyol indicate the absorption band at $3401 \mathrm{~cm}^{-1}$ attribute to hydroxyl group indicate the opening of epoxide ring.

The presence of compounds in the polymer is analysed and confirmed by FTIR spectral analysis. The $\mathrm{C}-\mathrm{H}$ stretching of $-\mathrm{CH}_{2}$ and $-\mathrm{CH}_{3}$ groups at $2854 \mathrm{~cm}^{-1}$ and $2923.9 \mathrm{~cm}^{-1} .20$
The absorption band at $3412 \mathrm{~cm}^{-1}$ associated with hydroxide functionality. The strong absorption band for the carbonyl group occurs at $1737 \mathrm{~cm}^{-1} .21$

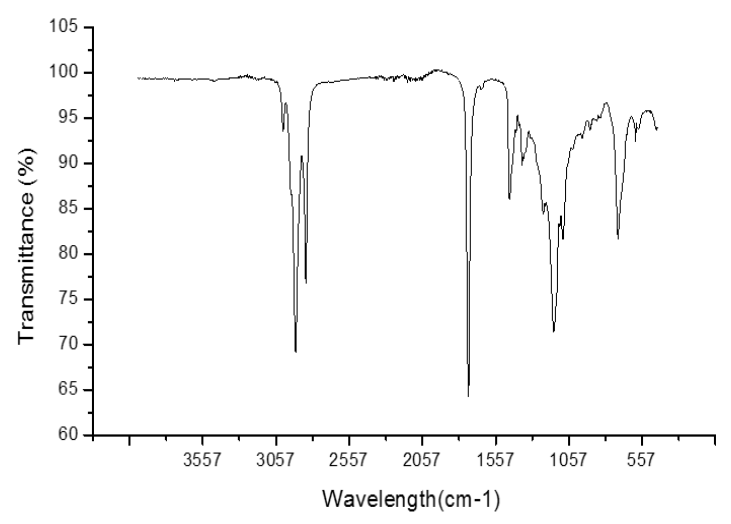

Fig. 1. FTIR Spectrum of Soyabean oil

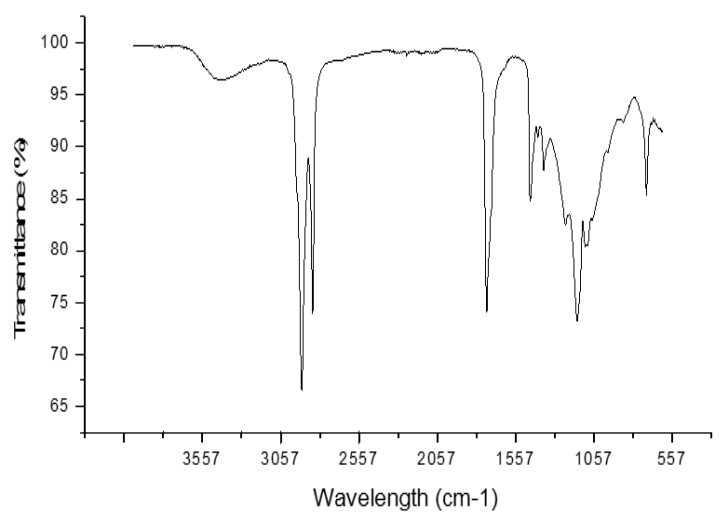

Fig. 2. FTIR spectrum of epoxidised soyabean oil

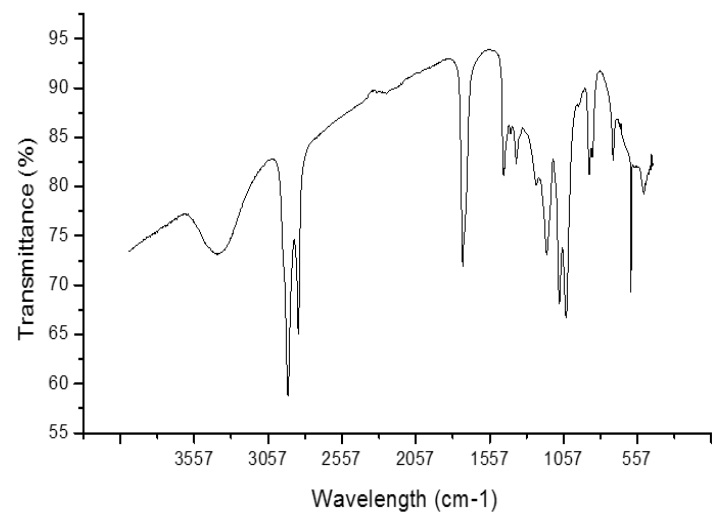

Fig. 3. FTIR spectrum of soyabean polyol

\section{${ }^{1} \mathrm{H}$ NMR spectral studies}

In this study the NMR spectrum of soyabean oil the peak at 4.3 to $5.4 \mathrm{ppm}$ shows the presence 
of methylene proton. The peak at 2.8 to $2.77 \mathrm{ppm}$ indicates the presence of hydrogen in ethylenic bond. The peak at 5.2 to $5.4 \mathrm{ppm}$ shows the olefinic proton present in soyabean oil. The chemical shift at 4.2 to $3.8 \mathrm{ppm}$ shows methylene protons of ester associated with triglyceride molecule. ${ }^{22}$

In the FTIR spectrum of epoxy resin shows the presence of epoxy linkage at $6.7 \mathrm{ppm}$. The peak appeared at $5.1 \mathrm{ppm}$ in soyabean polyol shows the presence of hydroxyl group. Thus the formation of polyol confirmed from these studies. The chemical shift at lower region from 5.3 to $0.8 \mathrm{ppm}$ support oleic, lonoleic and saturated fatty acids respectively. ${ }^{23}$ The Absorption band at 3.1-3.2 ppm is due to the deshielding effects of hydroxyl and carboxylate ester linkages. ${ }^{24}$

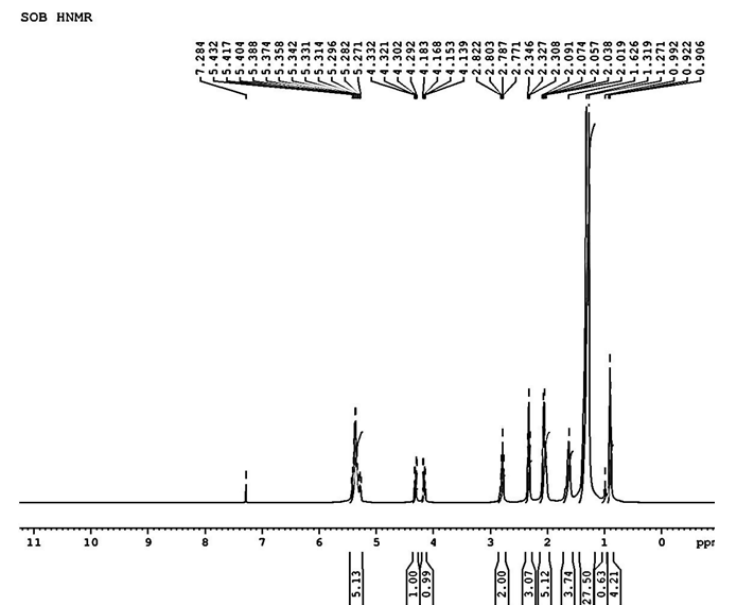

Fig. 4. ${ }^{1} \mathrm{H}$ NMR spectrum of soyabean oil

PXY HNMR

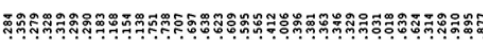

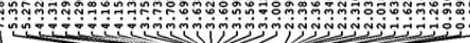

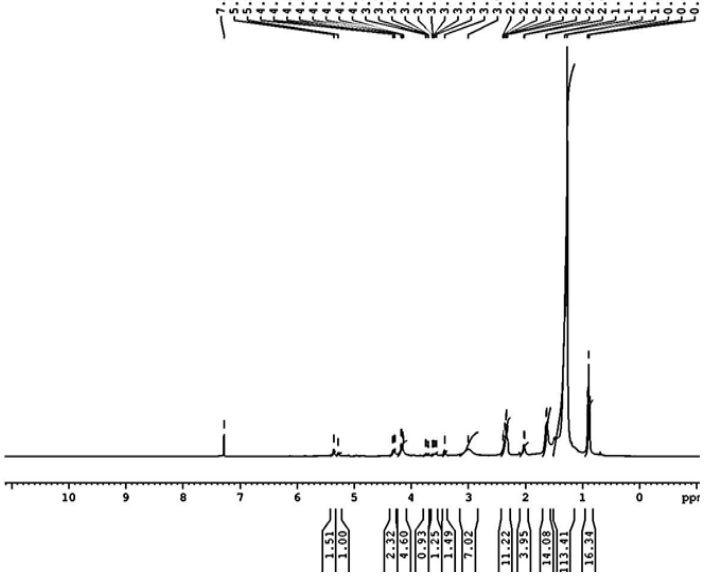

Fig. 5. ${ }^{1} \mathrm{H}$ NMR spectrum of epoxidised soyabean oil

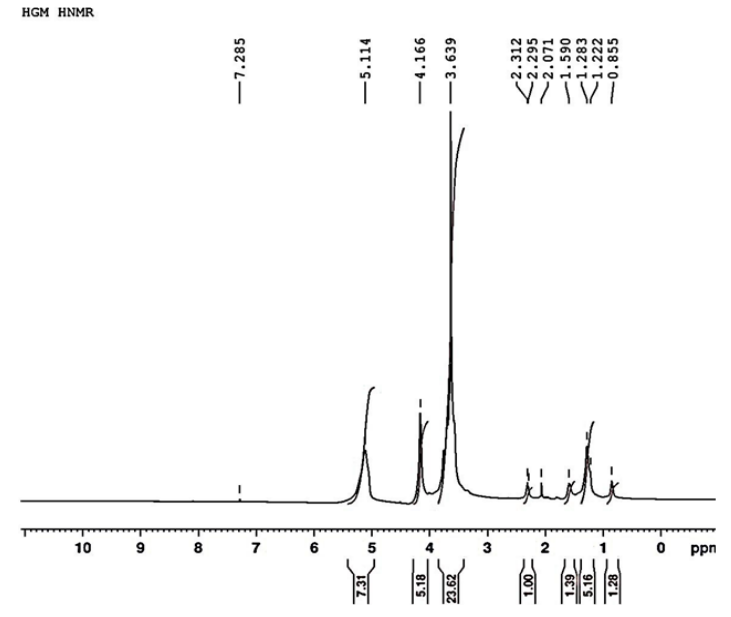

Fig. 6. ${ }^{1} \mathrm{H}$ NMR spectrum of soyabean polyol

\section{Mechanical properties}

The tensile properties in terms of tensile strength, percentage of elongation and young's modulus evaluated from the Table 2 .

Table 2: Mechanical properties of Polyurethane thin film

\begin{tabular}{cccccc}
\hline $\begin{array}{c}\text { Serial } \\
\text { number }\end{array}$ & $\begin{array}{c}\text { Polyurethane Hardness } \\
\text { (NCO/OH) }\end{array}$ & $\begin{array}{c}\text { Tensile Elongation } \\
\text { strength }\end{array}$ & $\begin{array}{c}\text { Young's } \\
\text { modulus }\end{array}$ \\
\hline 1 & PU (1:2) & 70.8 & 1.51 & 24.7 & 0.075 \\
2 & PU (1:3) & 71.4 & 2.75 & 15.84 & 0.081 \\
3 & PU (1:4) & 99.8 & 2.89 & 11.83 & 0.09 \\
\hline
\end{tabular}

The polyurethane film of different concentration is synthesised. They possess good tensile strength and strength increases with increase in concentration. This is due to higher crosslink density of the rigid polyurethane. In the present work the hardness of the polyurethane film increases with increase in concentration. This is due to the fact that as the chain length decreases the cross link density increases which results into more rigid network with better mechanical properties. The percentage of elongation is increases with increase in concentration. The increase in elongation is due to the increase in length of soft segment that imparts flexibility. ${ }^{25}$ The tensile strength of Polyurethane composites from resin and polyol increases and percentage of elongation decreases when compared to polyurethanes. It is due to the increase in crosslink density which influences the rigid polyurethane network with better mechanical properties ${ }^{26}$. 


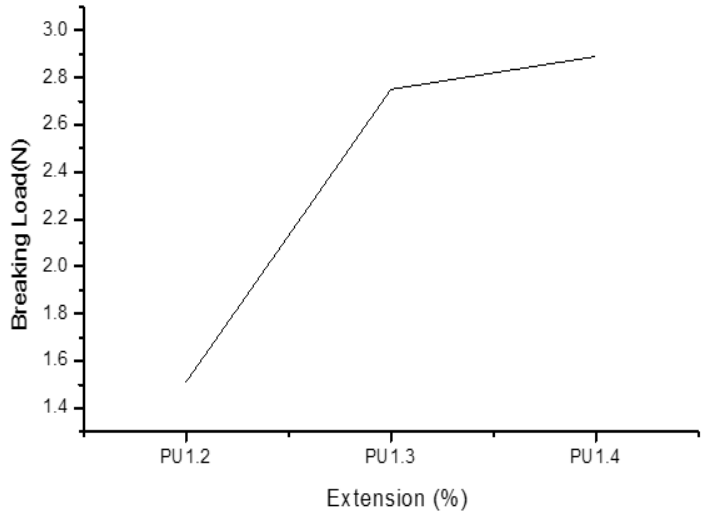

Fig. 7. Tensile strength

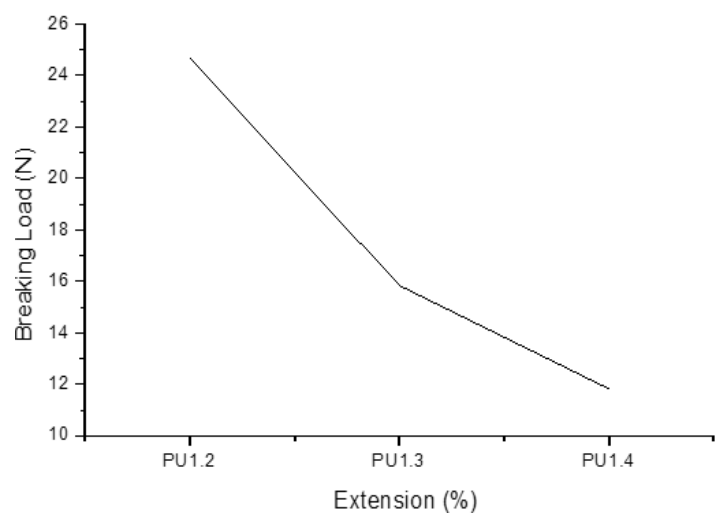

Fig. 8. Elasticity Properties

The tensile strength of polyurethane based on IPDI possess better mechanical properties than those of the HMDI based polyurethane. This may due to the fact that the aliphatic HMDI is flexible and symmetric open chain structure with two primary isocyanate groups whereas the cyclo aliphatic IPDI possess unsymmetric structure in which one the isocyanate groups are secondary in nature. ${ }^{27}$ The tensile strength of polyurethane films depends on the absorption, conversion of impact energy and the elasticity of the molecular chains. ${ }^{28}$

\section{Chemical Resistance}

The thin film of polyurethane is tested under different solvents at regular time intervals. The polar solvents such as sodium hydroxide, sodium chloride and hydrochloric acid used for swelling analysis. The polyurethane film was unaffected with water while slightly soluble in $20 \%$ sodium chloride and $0.1 \mathrm{~N}$ hydrochloric acid. Polyurethane possess greater effect in $0.1 \mathrm{M}$ sodium hydroxide. The swelling test is a method used measure crosslink density, which is calculated by using Flory Rehner theory based on the chain network. The cross link density is defined as the number of cross linking per unit volume. ${ }^{29}$

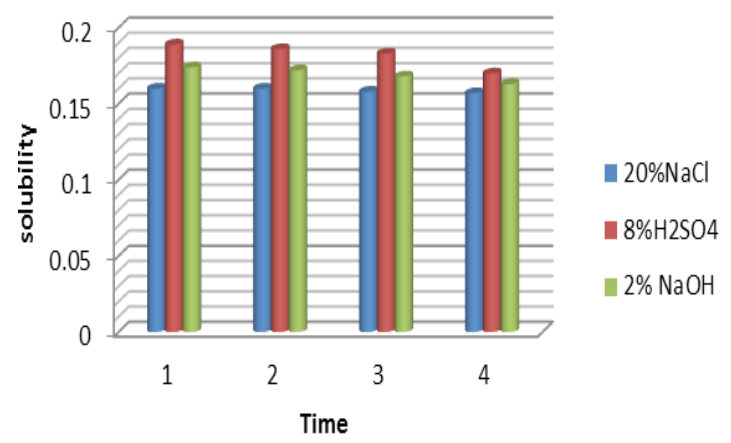

Fig. 9. Swelling of polyurethane against polar solvents

The degree of swelling and sol content is analysed using ether, chloroform, acetone,ethanol, toluene and DMSO. The swelling percentage was calculated by using the formulae,

Swelling percentage $=[(\mathrm{Ws}-\mathrm{W} 0) / \mathrm{W} 0] \times 100$.

$\mathrm{Ws}=$ Weight of the swellen polymer, $\mathrm{W} 0=$ Weight of the dried polymer.

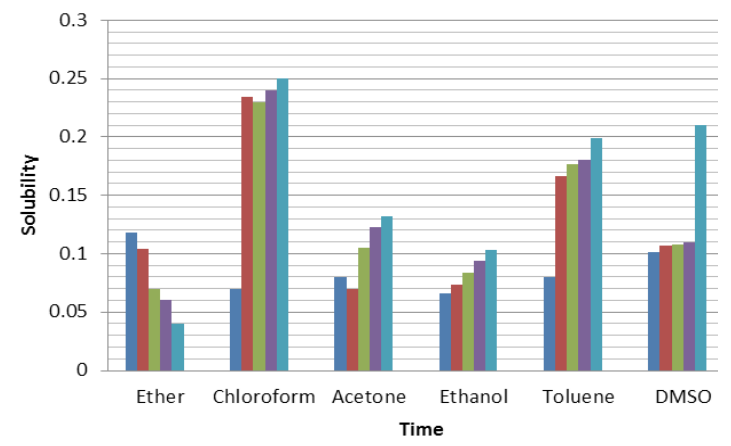

Fig. 10. Swelling behaviour of polyurethane against organic solvents

The polyurethane showed good resistance towards acids, alkalies and solvents too. It is also found to be the alkali resistance of samples are more than acid resistance..$^{30}$

\section{Soil burial test}

Soil burial test helps to identify the environmental resistance of the polymer. The polyurethane film of $1 \mathrm{~cm} \times 2 \mathrm{~cm}$ dimension is buried into the soil and water is sprayed over the soil for bacterial attack. The weight loss of the polymer was calculated after 10 days. Similarly the weight 
loss is taken out between four weeks. After 72 days the polymer film is removed from the soil. Then the percentage of weight loss is calculated by using the formulae.

Percentage of weight loss $=$ WO-Ws $/$ WO $\times 100$ Where, Wo = Initial weight of the polymer, Ws = weight of the polymer after 10 days.

Sem analysis is carried out to find out the biodegradability of the polymer.

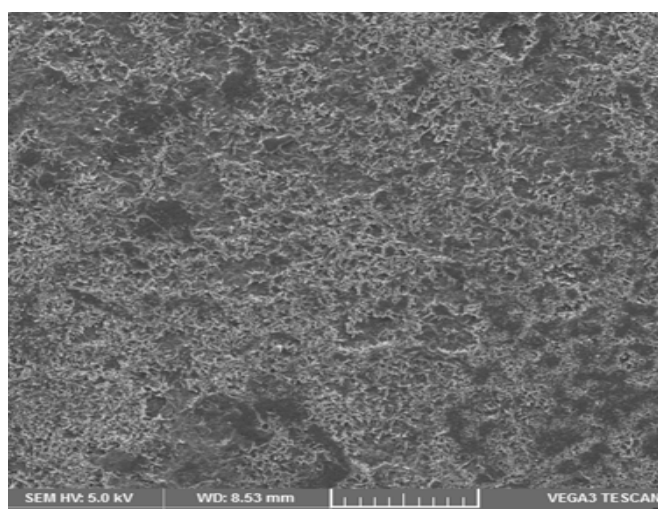

Fig. 11. SEM image of Polyurethane before soil burial test

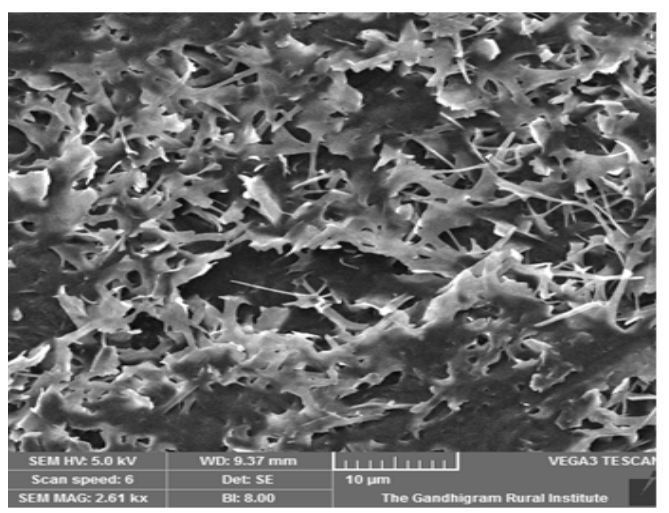

Fig. 12. SEM image of Polyurethane after soil burial test

\section{TG-DTA Analysis}

TGA, DTG and DTA measurements are carried out by a Perkin Elmer Thermal analysis. Initially $14.403 \mathrm{mg}$ of the Polyurethane film is scanned between $42-572^{\circ} \mathrm{C}$. The TGA thermogram for the polyurethane is shown in the figure. 14. In the first stage the weight loss occurs at $300^{\circ} \mathrm{C}$. The second stage shows the degradation temperature at 310 to $430^{\circ} \mathrm{C}$ with a weight loss of $5 \%$.

At $336.98^{\circ} \mathrm{C}$ the degradation starts and the weight loss of the polymer is $7.229 \%$. The weight loss of $19.47 \%$ occurs at $414.50^{\circ} \mathrm{C}$ indicate that the weight of the polymer increases.

In the present study Polyurethane films are thermally stable upto $100^{\circ} \mathrm{C}$ with $15 \%$ of weight loss of moisture retained in the sample. The first step of degradation of Polyurethane starts from vegetable oils followed by the liberation of carbondioxide. It is due to the formation of carbodiimide groups and the cleavage of carbamate bond takes place during the reaction ${ }^{31,32}$.

Table 3: Percentage of Weight loss at various temperature

\begin{tabular}{lrrrrrr}
\hline Sample/ Temperature & 100 & 200 & 300 & 400 & 500 & 600 \\
Weight loss & $15 \%$ & $60 \%$ & $95 \%$ & $100 \%$ & $90 \%$ & 150 \\
\hline
\end{tabular}

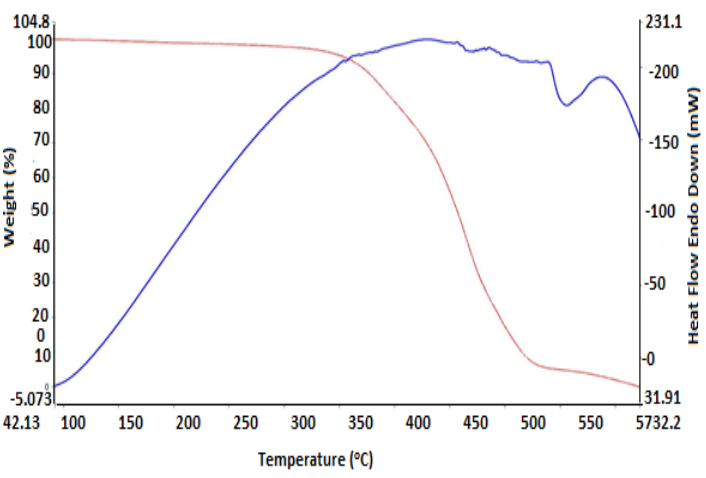

Fig. 13. TG-DTA Diagram of Polyurethane

Table 4: Physical properties of Soyabean oil

\begin{tabular}{|c|c|c|c|}
\hline Parameters & Soyabean oil & Epoxy resin & Polyol \\
\hline Saponification & 196 & 154 & 70.12 \\
\hline \multicolumn{4}{|l|}{ Value $(\mathrm{mg} / \mathrm{KOH})$} \\
\hline lodine Value & 130 & 100 & 56 \\
\hline Viscosity at $30^{\circ} \mathrm{C}$ & 34 & 115 & 120 \\
\hline Epoxy Value & 0.1 & 5 & 0.5 \\
\hline Hydroxyl number & - & - & 35 \\
\hline Acid value & 0.56 & 16.83 & 22.44 \\
\hline
\end{tabular}

\section{CONCLUSION}

The soyabean oil consist of unsaturated fatty acids such as oleic acid and linoleic acid. The characteristic studies such as FTIR and NMR shows the formation of intermediate products at different stages. The swelling analysis for polar and organic solvents at different time intervals. The polymer is unaffected by polar solvents and slightly affected by organic solvents. The biodegradability is confirmed by soil burial test. The percentage of 
weight loss is decreased with different time intervals. The polyurethane film possess tensile strength and hardness. The tensile strength increases with increase in concentration. The hardness of the polymer is increases with increase in concentration. The thermal degradation of polyurethane is studied by TG-DTA Analysis. The conclusion made on these studies are the synthesised polyurethane film is biodegradable and possess good mechanical strength and hardness. The rigid polyurethane is more stable than tough polyurethane.

\section{ACKNOWLEDGEMENT}

We would like to thank the following organisations to carried out the analysis work. School of chemical sciences, M.G. University Kottayam, IIRBS, Kottayam, SEM instrumentation centre, Gandhigram Rural University, Dindugal. STIC India, Cochin University, Kerala.

\section{REFERENCES}

1. Soto.M, Sebastin.M and Marquet.J, Photochemical Activation of extremely weak Nucleophiles. Highly Florinated Urethanes and polyurethane from polyfluoro alcohol, $J$. Org. Chem., 2014, 79, 5019-5027.

2. Saggese E.J, Scholnik F., Zubillaga M, J. Chem. Soci., 2013, 113-115.

3. Khoe T.H., Oety F.H., Frankel E.N., J. Am .Oil Soci., 1972, 49.

4. Chian K.S, Gan L.H, J. Appl. Poly. Sci., 1998, 68(3), 509-515.

5. Sursh kumar A., Karthik B., Dinakaran S. Raja pradeepan R, Int. Org. Sci. Res. 2014.

6. Katoch S., Sharma V and Kundu P. P, , Diffusion Fundamenta., 2011,

7. O.Bayer, Angew chem. Int.Ed 59, 1947.

8. Dutta.S.; Karak.N.; Synthesis and Characterization of polyurethane amide resins from from Nahar seed oil for surface coating applications - A renewable Resource Progress in Organic Coatings., 2005.

9. Yadav.S.; Zafar, FHasnat.; A, Ahmad. S. Polyurethane fatty amide resin from linseed oilA Renew. Res. Progress in Org. Res., 2009.

10. Lee, C.S, Ooi .T.L, Chuah, C.H.Ahmad, Synthesis of Palm oil based Diethanolamides J. Ame. Oil Chem. Soci., 2007, 84.

11. Muttaqa, Effect of flame retardant on polymeric materials , J. Flame ret. Mat., 2011.

12. Ward. F, Textile research J. Soci, Dyes and Colourist., 2010.

13. Akbas T, Beker U, Guner F.S, Erciyes AT, Styrenation of sunflower oil and linseed oils. Journal of Appl. poly. Sci., 2003.

14. H.Yeganesh, P.H. Talemi, Preparation and properties of biodegradable polyurethane networks based on castor oil and polyethylene glycol. Polymer degradation and stability., 2007.
15. Pfister.D.P, .Xia.Y, and Larock.R.C, Recent Advances in Vegetable oil based polyurethane. Chem. Sus. Chem., 2014.

16. Konga.X, Liu.G, Qi.H, Curtis.J.M, Preparation and Characterization of high solid polyurethane coating systems based on vegetable oil derived polyols. Progress in Organic Coatings., 2013.

17. Gopalakrishnan.S and Linda Fernando.T, Effect of aliphatic diisocyanates on the properties of Cardanol based polyurethanes, Scholars Research Library., 2010.

18. Taj.S, Munawar.M.A and Khan.S, Proceeding of Pakistan Academy of science., 2007.

19. Beltran.A.A and Boyaca.L.A, University of Colombia, Latin Ame. Appl. rese., 2011, 41.

20. Mohapatra.S, Mohanty.N, Satapathy.J.N, Guru.B.N and Pal. N. C, Studies on effect of variation of $\mathrm{NCO} / \mathrm{OH}$ molar ratio $\mathrm{PU} / \mathrm{CDM}$ weight ratio on thermal stability of IPNs derived from linseed oil based MEP-TDI-cardanol based DM of 2-chloroaniline, J. Chemi. and Phar. Res., 2014, 6(4), 1126- 1134.

21. Jayewardhana WGD, Perera GM, Edirisinghe DG, Karunanayake L, Study on natural oils alternative processing aids and activators in carbon black filled natural rubber. Journal of the National Science Foundation of Sri Lanka., 2009, 37(3): 187-193.

22. Crews.C, Hough.P, Godward J, Study of the main constituents of some authentic hazelnut oils. J. Agri. Food Chemi., 2005, 53(12).

23. Gurdeniz.G, Ozen.B, Detection of adulteration of extra virgin olive oil by chemometric analysis of mid infrared spectra data, Food Chemistry., 2009, 116(2).

24. Mythili CV, Retna, Gopalakrishnan S, Synthesis, mechanical, thermal and chemical 
properties of polyurethanes based on cardanol. Bulle. of Mat Sci., 2004, 27(3): 235-241.

25. Joseph.J, Baker.C, Mukkamala. S, Chemical shifts and lifetime for nuclear magnetic resonance analysis of bio fuels. Energy and fuels., 2010, 24(9), 5153-62.

26. Gopala Krishnan.S, Fernado.T.L, Bul.Mat. Sci., 2012, 35(2), 243.

27. Gite.V.V, Mahulikar.P.P ,Hundiwale.D.G and Kapadi.U.R, Polyurethane coatings using trimer of isophorone diisocyanate, Journal of Scientific and Industrial Res., 2003.

28. Chan-Chan. L.H, Solis Correr, Vargas Coronado.R.F, Cervantes, Cauich- Rodrigez, Quintana, Bartolo Perez, Degradation studies on segmented polyurethanes prepared from HMDI, PCL and different chain extenders, $J$ of Acta Biomaterialia., 2010, 6, 2035-2044.

29. Shaffer M.W, Potter.T.A, Venham. L. D and Schmitt P. D, US Patent 31423, 2015.

30. Niklas Wingborg, Polym. Testing., 2002, 21, 283-287.

31. Javni.I, Petrovic.Z.S, Thermal stability of Polyurethane based on Vegetable oils, Appl. Poly. Sci., 2000, 77, 1723-1734.

32. Tien.Y.I, Wei.K.H, The effect of Nano sized silicate layers from Montmorillonite on Glass Transition, Dynamic, Mechanical and Thermal degradation properties of segmented polyurethane, J. App. Poly Sci., 2002. 